\title{
PERENCANAAN DAN PEMBUATAN RANGKAIAN DAYA STARTING MOTOR 3 FASA ,380 VOLT ,50 Hz, 3 HP DENGAN METODA BINTANG (Y) - SEGITIGA $(\Delta)$
}

\author{
Ridho Andreansyah, R. Ahmad Cholilurrahman \\ Program Studi Teknik Elektro, Fakultas Teknik, Universitas Muhammadiyah Surabaya \\ Jl. Sutorejo No.59, Dukuh Sutorejo, Mulyorejo, Surabaya,Jawa Timur 60113 \\ e-mail : cholilurrahman_r@yahoo.com
}

\begin{abstract}
Abstrak - Rangkaian daya untuk motor induksi 3 fasa, $380 \mathrm{~V}, 50 \mathrm{~Hz}, 3 \mathrm{HP}$ dengan metoda bintangsegitiga merupakan rangkaian yang digunakan untuk menyalurkan daya pada motor listrik. Permasalahannya adalah untuk mengendalikan motor induksi diperlukannya rangkaian daya, dimana starting awal motor memberikan dampak arus yang besar. Tujuan penelitian ini adalah untuk dapat melakukan starting pada motor 3 fasa dengan metoda bintang(Y) - segitiga $(\Delta)$, Sebagai evaluasi dibuatnya suatu rangkaian daya metoda bintang segitiga, dimana hubung bintang digunakan untuk mengurangi arus starting yang besar, serta hubung segitiga digunakan untuk menstabilkan arus motor menjadi arus nominal sesuai nameplate motor. Hasil akhir menunjukkan bahwa untuk membuat panel distribusi terlebih dahulu yang dilakukan yaitu membuat perencanaan yang meliputi, perhitungan beban yang terpasang, pemilihan MCB sesuai dengan beban, pemilihan luas penampang sesuai dengan beban dan jenis kabel. Dimana dinyatakan dari sumber jala-jala 3 fasa, $380 \mathrm{~V}$ yang dialirkan ke dalam rangkain daya untuk kendali motor 3 fasa, $380 \mathrm{~V}, 3 \mathrm{HP}, 50 \mathrm{~Hz}$ metoda bintangsegitiga, diketahui bahwa beban yang terpasang $3 \mathrm{HP}$, arus pada hubung bintangnya 7,36 A, arus segitiga ataupun arus pada beban 4,26A, MCB yang dipakai memiliki kapasitas 17,04A, serta luas penampangnya $4,8 \mathrm{~mm}^{2}$ dengan jenis kabel NYM.
\end{abstract}

Kata kunci: Rangkaian Daya, Motor 3 Fasa, Metoda Bintang - Segitiga

\begin{abstract}
Power circuit for induction motor 3 Phase, $380 \mathrm{~V}, 50 \mathrm{~Hz}$, using star $(\mathrm{Y})$ - triangle $(\Delta)$ method is the circuit that is used to supply power to electric motor. The problem is to control an induction motor power is needed, and the first motor gives a big current impact. The objective of this study is to do the starting to 3 phase motor using star $(Y)$ - triangle $(\Delta)$ method where the star connection is used to stabilize the motor current into nominal current subject to the motor nameplate. The final finding indicates that before making a panel of distribution a planning must be prepared first, including couting the fixed load, choosing MCB subject to the load, choosing area of cross section subject tp load and type of cable. From the source of network of 3 phase, $380 \mathrm{~V}$ supplied to power circuit for the motor control of 3 phase, $380 \mathrm{~V}$, $3 \mathrm{HP}, 50 \mathrm{~Hz}$, with the star-triangle method, it is found out that the fixed load is $3 \mathrm{HP}$, the current on the star connection is 7.36 A, current of triangle or current of load 4.26 A, the used MCB is with capacity $17.04 \mathrm{~A}$ and the area of cross section is $4.8 \mathrm{~mm}^{2}$ with type of cable NYM.
\end{abstract}

Keywords: Power circuit, 3 Phase Motor, Star-Triangle Method

\section{PENDAHULUAN}

Di dalam pengoperasian motor induksi 3 fasa biasanya selalu dilengkapi dengan suatu panel listrik yang di dalamnya terdapat rangkaian daya. Rangkaian daya sendiri berfungsi untuk menyediakan atau menyalurkan daya pada motor listrik. Dalam penelitian ini rangkaian daya yang akan digunakan adalah rangkaian daya hubung bintang segitiga. Dimana cara kerjanya yaitu saat start awal motor hubungan bintang dan selanjutnya motor hubung segitiga. Permasalahannya adalah untuk mengendalikan motor induksi diperlukannya rangkaian daya, dimana starting awal motor tersebut memberikan dampak arus yang besar, maka akan membutuhkan daya yang sangat tinggi serta menyebabkan motor mudah rusak, karena memberikan tenaga daya yang maksimal dan biaya terlalu mahal dengan adanya lonjakan arus daya. Dalam menurunkan arus starting banyak metode yang digunakan, salah satunya 
adalah metode bintang-segitiga. Sebagai evaluasi dibuatnya suatu rangkaian daya metoda bintang segitiga, untuk mengukur arus rangkaian pengendali hubung langsung disebut juga Direct On Line (DOL) dengan metoda bintang - segitiga. Hubungan bintang difungsikan untuk mengurangi lonjakan arus listrik yang besar ketika motor mulai dihidupkan, karena motor listrik membutuhkan torsi awal yang besar agar dapat melawan inersia dan inersia bebannya dengan keadaan diam, dimana untuk mengurangi torsi awal menggunakan hubung bintang. Hubungan segitiga difungsikan untuk menstabilkan arus motor menjadi arus nominal. Untuk membuat panel distribusi terlebih dahulu yang dilakukan yaitu membuat perencanaannya yang meliputi, perhitungan beban yang terpasang, pemilihan MCB sesuai dengan beban, pemilihan luas penampang sesuai dengan beban, jika semua instalasi sudah terpasang maka yang harus dilakukan adalah melakukan pengujian terhadap instalasi apakah ada instalasi yang tidak terpasang dengan baik atau terjadi trouble shooting, yang dapat menyebabkan terjadinya hubungan singkat. Sasaran penelitian ini perencanaan dan pembuatan rangkaian daya starting motor 3 fasa, $380 \mathrm{~V}, 50 \mathrm{~Hz}$, dengan metoda bintang $(\mathrm{Y})$ - segitiga $(\Delta)$.

\section{TINJAUAN PUSTAKA}

Perencanaan dan Pembuatan dalam panel, memerlukan rumusan masalah, tujuan dan penyelesaian masalah. Baik dalam material ataupun dalam struktural dalam mendesain suatu barang. Dimana dalam setiap perencanaan yang digunakan, harus dicermati sedetail mungkin agar tidak terjadi kesalahan dalam perancangan dan pembuatan barang tersebut dan sesuai dengan PUIL 2000 pada BAB4 Perencanaan Instalasi Listrik. Perencanaan dan Pembuatan sangat perlu dikarenakan agar tidak terjadi kesalahan yang fatal dalam penggunaan panel dan juga mengurangi biaya dalam pembuatan panel. Pengoperasian motor induksi diharapkan dapat beroperasi secara normal sesuai dengan karakteristik kerja yang dikehendaki, namun tidak dapat di pungkiri adanya gangguan yang dapat menimbulkan kerusakan terhadap rangkaian kerja motor, salah satunya adalah jatuh tegangan jala-jala. Salah satu kelemahan dari Penggunaan panel adalah tidak terstrukturnya perancangan dan pembuatan panel, sehingga tidak terbentuknya rancangan yang baik dalam penggunaan panel dan mengakibatkan cepat rusaknya panel, waktu pemakaian juga tidak bertahan lama serta bahaya jika terjadinya hubung singkat, hilang fasa ataupun arus beban lebih yang menyebabkan konsleting.[1]

Rangkaian daya dapat didefinisikan sebagai rangkaian yang merupakan jalur tegangan utama motor bisa $220 \mathrm{~V}, 380 \mathrm{~V}, 660 \mathrm{~V}$, bahkan $6.6 \mathrm{kV}$, dan sebagainya. Aliran arus ke motor ditentukan oleh kondisi anak kontak dari kontaktor utama. gambaran rangkaian beban dan kotak-kontak utama kontaktor serta contact breaker dan komponen pengaman yang dihubungkan ke arus beban.Dan rangkaian utama sendiri bekerja sesuai dengan bantuan rangkaian kontrol.Dalam perangkaian rangkaian utama harus kuat dengan penghantar yang sesuai dengan PUIL 2000 sehingga dapat bekerja sesuai dengan fungsinya. rangkaian daya dapat dikatakan sebagai hubungan antara komponen yang membentuk sebuah konfigurasi rangkaian, yang akan menghasilkan tanggapan rangkaian yang diharapkan. Jadi harus ada yang dikendalikan, yang merupakan suatu rangkaian fisis, yang biasa disebut dengan kendali (plant).Masukan dan keluaran merupakan variable ataua besaran fisis.Keluaran merupakan hal yang dihasilkan oleh kendali, artinya yang dikendalikan; sedangkan masukan adalah yang mempengaruhi kendali, yang mengatur keluaran. Kedua dimensi masukan dan keluaran tidak harus sama. [2]

Motor induksi adalah motor listrik arus bolak balik (ac) yang putaran rotornya tidak sama dengan putaran medan putar pada stator, dengan kata lain putaran rotor dengan putaran medan pada stator terdapat selisih putaran yang disebut slip. Serta suatu alat penggerak yang paling banyak digunakan dalam dunia industri. Hal ini dikarenakan motor induksi mempunyai konstruksi yang sederhana, kokoh, harganya relatif murah, serta perawatannya yang mudah, sehingga motor induksi mulai menggeser penggunaan motor DC pada industri. Motor induksi memiliki beberapa parameter yang bersifat non-linier, terutama resistansi rotor, yang memiliki nilai bervariasi untuk kondisi operasi yang berbeda. Hal ini yang menyebabkan pengaturan pada motor induksi lebih rumit dibandingkan dengan motor DC. Motor induksi 3 phasa harus dijalankan dengan alat pengasut, hal ini disebabkan motor tersebut memiliki gulungan stator yang tahanannya rendah. Karena tahanannya rendah maka motor akan mengambil arus besar pada saat starting. Untuk industri yang mengoperasikan beberapa motor secara bersamaan, arus starting yang besar dari motor tersebut dapat menyebabkan terjadinya overload disamping akan merusak gulungan stator itu sendiri. Karena itu pada saat menjalankan motor induksi 3 phasa harus menggunakan alat pengasut. Disini akan dibahas mengenai kendali motor induksi 3 phasa star delta, yaitu motor tersebut akan dihubungkan star saat starting, kemudian dengan timer akan dialihkan menjadi kondisi hubung delta pada saat jalan. Motor induksi bekerja berdasarkan induksi elektromagnetik dari kumparan stator kepada kumparan rotornya. Garis-garis gaya fluks yang diinduksikan dari kumparan stator akan memotong kumparan rotornya sehingga timbul emf (ggl) atau tegangan induksi dan karena penghantar (kumparan) rotor merupakan rangkaian yang tertutup, maka akan mengalir arus pada kumparan rotor. Motor listrik adalah alat untuk mengubah energi listrik menjadi energi mekanik.Alat yang berfungsi sebaliknya, mengubah energi mekanik menjadi energi listrik disebut generator atau dinamo. Motor listrik yang umum digunakan di dunia industri adalah motor listrik asinkron, dengan dua standar global yakni IEC dan NEMA. Motor asinkron IEC berbasis metrik (milimeter), sedangkan motor listrik NEMA berbasis imperial (inch), 
dalam aplikasi ada satuan daya dalam horsepower (hp) maupun kiloWatt (kW). [3]

Panel distribusi tenaga listrik berfungsi sebagai sistem pendistribusian tenaga listrik yang dihasilkan oleh sumber PLN dan atau diesel generator set. Panel distribusi terdiri dari berbagai peralatan listrik yang difabrikasi / diinstalasi menjadi rangkaian kontrol dan proteksi terhadap sumber tegangan dan beban, dengan komponen / peralatan listrik sebagai berikut :

\section{A. Isolator}

Isolator terdiri dari bahan porselin yang diapit oleh elektroda - elektroda dengan demikian isolator terdiri dari sejumlah kapasitansi - kapasitansi diperbesar oleh terjadinyalapisan yang menghambat listrik karena kelembaban udara, debu, dan lain-lain. Karena kapasitansi ini distribusi tegangan pada gandengan isolator tidak seragam, maka tegangan diperbaiki dengan memasang tanduk busur api. Tegangan lompatan api pada isolator terdiri dari tegangan lompatan api (flash over) frekuensi rendah impuls dan tembus dalam minyak (Surdia dan saito, 1999).

Pada isolator tegangan tinggi yang dipasang di daerahdaerah yang banyak mengandung polusi, bahan - bahan kotoran yang dapat menyebabkan terjadinya flash over dapat berasal baik dari polusi alam antara lain : es, salju, garam (pengotoran oleh air laut), debu, pasir dan lain-lain. Macam - macam polusi yang dapat menimbulkan flash over adalah debu semn (cement dust), abu terbang (fly ash), abu garam-garaman (potash), kapur (limestone), batu tahu (gypsum), dan kumpulan bahan-bahan lain (sirait dan triyono, 1982). Bahan-bahan polusi ini teridir dari dua komponen, yaitu : komponen konduktif dan komponen inert (lemban). Hampir semua komponen konduktif terdiri atas ion - ion garam seperti : Sodium Chlorida, Magnesium, Sodium Sulfat, dan lain - lain.

Garam - garam ini ketika berbentuk larutan mempengaruhi tegangan flash over, karena memberikan lapisan yang bersifat konduktif pada permukaan isolator. Beberapa komponen konduktif, terutama yang berasal dari pengotoran industri, adalah larutan gas seprti : Sodium Dioksida. Polusi dalam bentuk ini sulit untuk dideteksi, karena jika permukaan isolator mengering, gas yang ada akan lenyap. Komponen inert adalah suatu bahan padat yang tidak dapat larut sebagai ion - ion, komponen inert ini dapat menurunkan ketahanan listrik. Bahan - bahan inert dapat bersifat menyerap air hidrofilic, sifat ini dapat menaikkan laju pembasahan isolator. Jenis komponen inert (penyerap air) antara lain : lempung (keramik), silica dioksida, dan semen organik. Sedangkann yang termasuk bahan air (hydroponic) adalah gemuk dan oli, bahan bahan anti air ini dapat menyebabkan air terpecah menjadi butiran - butiran yang kemudian memecah lapisan konduktif pada permukaan isolator.

1. Papan Panel

2. Indikator dan Metering

3. Mini Circuit Breaker (MCB)

4. Kontaktor

\section{Thermal Overload Relay (TOR) \\ 6. Luas Penampang}

1. Papan Panel ialah suatu perlengkapan atau peralatan listrik yang berfungsi sebagai pengendali, pengubung dan pelindung serta membagi tenaga listrik dari sumber tenaga listrik seperti; pembangkit, gardu induk, gardu distribusi dan transformator ke saluran pelayanan atau ke pelanggan.

- Fungsi Panel adalah :

a. Untuk mengendalikan sirkuit dilakukan oleh saklar utama

b. Untuk melindungi sirkuit dilakukan oleh fase/pelebur

c. Untuk membagi sirkuit dilakuan oleh pembagian jurusan ataupun kelompok.

- Syarat - syarat pemasangan panel adalah :

a. Sehubungan dengan itu syarat PHB juga menentukan bahwa di bagian depan, lorong dan sisi kiri kanan PHB harus terdapat ruang bebas selebar sekurang-kurangnya 0,75 meter untuk tegangan rendah atau 1 meter pada tegangan menengah dan tinggi PHB sekurang-kurangnya 2 meter.

b. Lorong yang di sisi kanan kirinya terdapat instalasi listrik tanpa dinding pengaman, lebarnya harus sekurang-kurangnya 1,5 meter.

c. Di sekitar PHB tidak boleh diletakkan barang yang mengganggu kebebasan bergerak.

d. Untuk pemasangan pada dinding di tempat umum lemari dan kotak PHB harus dipasang pada ketinggian sekurang-kurangnya 1,2 meter dari lantai. Pada instalasi perumahan ketinggian ini ditetapkan 1,5 meter dari lantai.

- Macam - macam panel menurut tegangan :

a. Panel Tegangan Rendah

b. Panel Tegangan Menengah

c. Panel Tegangan Tinggi

2. Pada panel dibutuhkan peralatan / instrument yang dipasang untuk melakukan monitoring kelistrikan yang ada. Suatu panel distribusi listrik umumnya dipasang metering yang standart yaitu : Ampere meter, Voltmeter, Kw meter, Frekuensi meter, Cos phi meter, dan untuk panel generator set yang bekerja paralel digunakan Zero volt meter, Double volt meter, dan synkronoskop, dan juga dilengkapi dengan indikator lampu (pilot lamp).

3. Panel distribusi membutuhkan peralatan listrik yang berfungsi sebagai pengaman terhadap terjadinya gangguan yang disebabkan oleh hubung singkat (short circuit) dan pembebanan yang melebihi kapasitas arus yang terjadi secara cepat (overloading), keandalan dari suatu breaker ditentukan dari kecepatan memutus jika terjadi gangguan dan kemampuan untuk menahan arus hubung singkat secara cepat. Dalam panel distribusi tegangan rendah terdiri dari bermacam - macam 
breaker sesuai dengan kapasitasnya yaitu antara lain : miniature circuit breaker (MCB), moulded circuit breaker (MCCB), no fuse breaker (NFB), NT fuse, air blast circuit breaker (ACB). yang mempunyai berbagai kutub dari satu sampai empat kutub. Dalam memilih kutub circuit breaker, hal - hal yang harus dipertimbangkan adalah :

- Karakteristik sistem dimana circuit breaker tersebut dipasang.

- Kebutuhan akan kontinuitas pelayanan sumber daya listrik.

- Aturan dan standar proteksi yang berlaku.

Aturan instalasi listrik yang berlaku seperti PUIL, BKI harus diikuti. Standar yang diacu baik local atau internasional seperti SPLN, IEC 60947-2 harus diperhatikan. Penanaman tipe MCB beragam, tergantung pada pabrik pembuat, data pemakaian yang perlu adalah karakteristik tiap MCB untuk disesuaikan dengan kebutuhan sistem.

4. Kontaktor adalah peralatan listrik yang berfungsi untuk memutus atau menghubungkan rangkaian listrik. Kontaktor terdiri dari 3 bagian pokok, yaitu : kontak utama, kontak bantu, dan koil magnetic. Prinsip kerja kontaktor berdasarkan induksi elektromagnetik dimana koil magnetic kontaktor tersebut di supply sumber tegangan listrik AC/ DC, pada kumparan tembaga tersebut terjadi induksi elektromagnetik sehingga dapat menarik bahan ferro magnetic yang ada di dekatnya (prinsip magnet buatan). Kapasitas penghubung dan pemutus suatu kontaktor dapat dilihat dari data teknik dari suatu kontaktor itu sendiri, jadi jika suatu kontaktor menghubungkan arus listrik yang melebihi kemampuan hantar arusnya (KHA) maka kontaktor tersebut akan leleh dan mengakibatkan hubung singkat. Sistem pengontrolan motor listrik semi otomatis yang menggunakan alat kontrol kontaktor magnet memerlukan alat bantu lain agar fungsi pengontrolan berjalan dengan baik seperti: tombol tekan, thermal overload relay dan alat bantu lainnya. Kontaktor magnet banyak digunakan untuk mengontrol motormotor listrik 1 fasa dan 3 fasa, anatara lain untuk mengontrol motor dua arah putaran, strating bintangsegitiga, beberapa unit motor bekerja dan berhenti berurutan dan lain-lain.

Macam - macam kontaktor magnet :

1. Kontaktor magnet arus searah (DC)

2. Kontaktor magnet arus bolak balik (AC)

5. Overload adalah komponen pengaman khusus motor listrik yang berfungsi untuk memutuskan jaringan listrik jika terjadi beban lebih. Overload Motor Protection, yang dimaksud motor ini adalah electric motor yang oleh orang awam disebut dinamo. Dan disini dikhususkan yang terjadi pada motor AC 3 phase. Fungsi dari motor ini adalah sebagai penggerak atau untuk mengkonversi energi listrik menjadi mekanik/ gerak seperti lift, conveyor, blower, crusher dll. Secara umum sistem kerja alat tersebut dapat dibagi menjadi dua yaitu dengan thermal dan elektronik.

6. Tiga hal penting untuk memilih Overload :
a. Kemampuan hantar arus (KHA)
b. Tegangan kerja nominal
c. Nilai nominal arus beban lebih (seting arus beban lebih).

7. Luas penampang Adalah peralatan listrik yang berfungsi untuk penghantar / konduktor listrik yang berfungsi untuk mendistribusikan listrik dari suatu sumber ke suatu beban. kabel mempunyai luas penampang yang berbeda-beda tergantung dari kemampuan hantaran arus (KHA) yang digunakan. Perencanaan pemasangan power kabel / kontrol kabel harus mempertimbangkan terhadap suhu ruang dan pemasangan di udara atau di dalam tanah (underground). Jenis penghantar yang selama ini dipakai untuk kabel tegangan rendah / kabel di bawah tegangan kerja $1 \mathrm{kV}$ dengan isolasi PVC. Jenis kabel yang digunakan antara lain :

a. NYY, jenis ini dapat digunakan sebagai kabel tenaga untuk instalasi industri dan dalam lemari hubung bagi. Apabila diperkirakan tidak akan ada gangguan mekanis, kabel ini dapat juga ditanam dalam tanah asal diberi perlindungan secukupnya.

b. NYM, jenis kabel ini untuk instalasi penerangan dimana dalam pemasangannya tidak merusak isolasi PVC nya, tapi kabel jenis ini tidak boleh ditanam dalam tanah karena alasan keamanan dimana isolasinya tidak untuk kabel tanam.

c. NYA, kabel inti tunggal dengan kawat tembaga berisolasi PVC seperti NYY.

d. NYAF, berupa kabel inti tunggal dengan kawat tembaga berisolasi PVC fleksibel.

e. BC (Bore Copper), digunakan untuk pentanahan berupa kabel tanpa isolasi, biasanya disambung dengan elektrode yang ditanam dalam tanah.

Menentukan besarnya ukuran luas penampang kabel pada rangkaian daya :

$$
\mathrm{A}=\frac{\sqrt{3} \cdot \mathrm{L} \cdot \mathrm{IL} \cdot \cos \varphi}{r \mathrm{YV} \cdot \mathrm{rV}}
$$

$\mathrm{A}=$ Luas penampang kabel $\left(\mathrm{mm}^{2}\right)$

$\mathrm{I}_{\mathrm{L}}=$ Arus pada rangkaian daya (Ampere)

$\mathrm{L}=$ Panjang kabel $(\mathrm{m})$

$\operatorname{Cos} \varphi=$ Faktor daya motor

$\mathrm{rV}=$ Rugi tegangan (Volt)

$\mathrm{Y}=$ Daya hantar tembaga $=56$

$\mathrm{rV}=$ Rugi tembaga $=10^{-1}$

\section{METODOLOGI PENELITIHAN}

\section{A. Waktu dan Metode Penelitian}

Waktu pelaksanaan penelitian dari tanggal 1 November 2013 sampai dengan tanggal 30 November 2013, lokasi 
penelitian di Laboraturium Mesin Listrik, Jurusan Teknik Elektro, Fakultas Teknik Industri (FTI), Institut Teknologi Adhi Tama Surabaya (ITATS), yang beralamat di Gedung H, Lantai 4, Ruang H3-405 di jalan Arif Rahman Hakim 100 Surabaya.

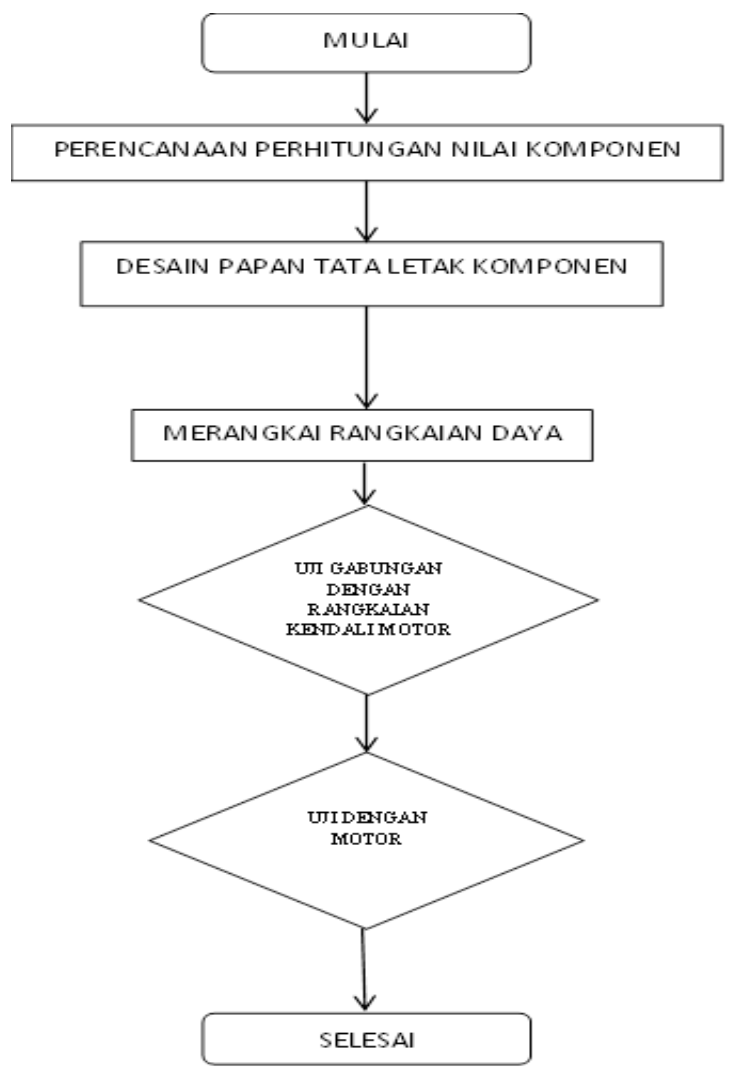

Gambar 1. Blok diagram Alur Penelitian

\section{B. Tahap Penelitian}

\section{Perencanaan Nilai Komponen}

Langkah - langkah menghitung arus komponen rangkaian bintang segitiga motor 3 fasa, 380 volt, $50 \mathrm{hz}$ menggunakan timer adalah sebagai berikut :

a. Menentukan arus awal dari sumber pasokan, untuk arus maksimum pada MCB 3 fasa :

$$
\mathrm{I}_{\mathrm{L}}=\frac{p}{\sqrt{a \cdot V \cdot \cos \varphi}}
$$

$$
\begin{array}{ll}
\mathrm{I}_{\mathrm{L}} & =\text { Arus pada tiap fasanya (Ampere) } \\
\mathrm{P} & =\text { Daya motor }(\text { Watt }) \\
\mathrm{V} & =\text { Tegangan Pasokan dari PLN 380V } \\
\operatorname{Cos} \varphi & =\text { Faktor daya motor }=0,8
\end{array}
$$

b. Menentukan arus pada saat hubung bintang :

$$
\begin{aligned}
& \left(\mathrm{V}_{\mathrm{Y}}\right)=\frac{V}{\sqrt{2}} \\
& \left(\mathrm{I}_{\mathrm{Y}}\right)=\frac{p}{\sqrt{\sqrt{2} \cdot V y \cdot \cos \varphi}}
\end{aligned}
$$

$\mathrm{I}_{\Delta}=$ Tegangan hubung bintang (Volt)
$\mathrm{I}_{\mathrm{Y}}=$ Arus pada saat hubung bintang (Ampere)

$\mathrm{V}=$ Tegangan pasokan dari PLN (Volt)

$\operatorname{Cos} \varphi=$ Faktor daya motor $=0,8$

Nilai arus pada saat hubung segitiga : $\mathrm{I}_{\Delta}=\mathrm{I}_{\mathrm{L}}$

c. Menentukan besarnya nilai batasan arus listrik MCB 3 phasa pada rangkaian daya hubung bintang segitiga :

$$
\begin{aligned}
& \mathrm{I}_{\text {start }}=4 \times \mathrm{I}_{\mathrm{L}} \\
& \mathrm{I}_{\mathrm{MCB}}=\mathrm{I}_{\mathrm{L}} \times 4
\end{aligned}
$$

$\mathrm{I}_{\mathrm{MCB}}=$ Nilai arus minimum pada MCB (Ampere)

$\mathrm{I}_{\mathrm{L}} \quad=$ Arus pada rangkaian kontrol (Ampere)

d. Menentukan besarnya nilai kapasitas arus listrik Magnetic Contactor 3 phasa pada rangkaian daya:

$$
\mathrm{I}_{\text {kontaktor }}=3 \times \mathrm{I}_{\mathrm{L}}
$$

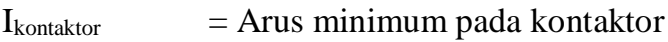

$$
\mathrm{I}_{\mathrm{L}} \quad=\text { Arus pada rangkaian daya }(\mathrm{A})
$$

e. Menentukan nilai batasan arus listrik Overload pada rangkaian daya :

$$
\mathrm{I}_{\text {overload }}=\frac{\mathrm{L}}{\sqrt{3}} \times \mathrm{I}_{\mathrm{L}}
$$

$\mathrm{I}_{\text {overload }}=$ Arus pada overload

$\mathrm{I}_{\mathrm{L}} \quad=$ Arus pada rangkaian daya (Ampere)

f. Menentukan besarnya ukuran luas penampang kabel pada rangkaian daya:

$$
\mathrm{A}=\frac{\sqrt{3} \cdot \mathrm{L} \cdot \mathrm{IL} \cdot \cos \varphi}{r \mathrm{YV} \cdot \mathrm{rV}}
$$

$\mathrm{A}=$ Luas penampang $\mathrm{kabel}\left(\mathrm{mm}^{2}\right)$

$\mathrm{I}_{\mathrm{L}}=$ Arus pada rangkaian daya (Ampere)

$\mathrm{L}=$ Panjang kabel (m)

$\operatorname{Cos} \varphi=$ Faktor daya motor

$\mathrm{rV}=$ Rugi tegangan (Volt)

$\mathrm{V}=$ Daya hantar tembaga $=56$

$\mathrm{RY}=$ Rugi tembaga $=10^{-1}$

\section{Desain Papan Tata Letak Komponen Rangkaian Elektronika Daya}

Ditunjukkan oleh gambar dengan sistem daya bertegangan 380 volt, dengan komponen daya diantaranya kontaktor, kabel daya, mini circuit breaker (MCB),overload dan amperemeter . Rangkaian daya dipasang secara vertikal dengan sistem kuda-kuda, semua komponen daya dipasang pada bahan acrylic berukuran $250 \mathrm{~cm} \times 150 \mathrm{~cm}$ sebagai isolasi terhadap induksi listrik agar operator tidak terkena tegangan listrik yang membahayakan dirinya atau lainnya. 


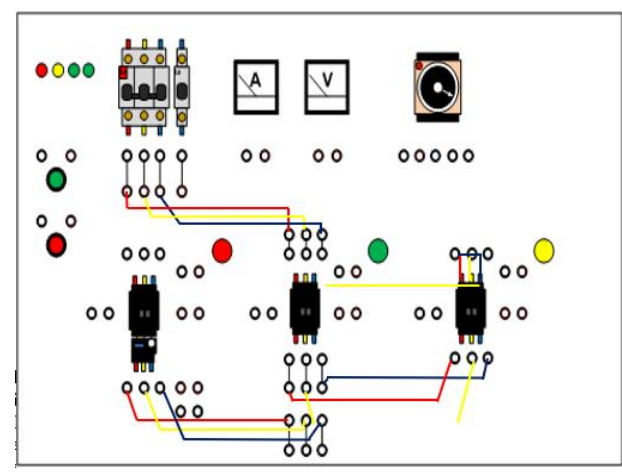

Gambar 2. Desain Papan Tata Letak Komponen

\section{HASIL PENGUJIAN PENGAMATAN}

\section{A. Menentukan Pemasangan Komponen}

Dalam pembuatan rangkaian daya, untuk pemilihan komponen- komponen yang akan digunakan sebaiknya terlebih dahulu mengetahui besar daya motor yang akan dioperasikan. Hal tersebut dikarenakan besar daya motor yang digunakan akan menjadi acuan untuk memilih kapasitas besar arus yang dapat dilalui oleh komponenkomponen pada rangkaian daya.

Menghitung nilai arus komponen rangkaian bintang segitiga motor 3 phasa 3 HP sebagai berikut :

a. Untuk menentukan besarnya nilai arus listrik pada rangkaian daya,maka perlu konversi satuan :

Daya $(\mathrm{P})=3 \mathrm{HP}=3 \times 746=2238$ Watt

Tegangan $(\mathrm{V})=380$ Volt

Faktor Daya $(\operatorname{Cos} \varphi)=0,8$

Nilai Arus Line $\left(\mathrm{I}_{\mathrm{L}}\right)=\frac{p}{\sqrt{2} \cdot V \cdot \cos \varphi}=\frac{228 \mathrm{~g}}{\sqrt{2} \cdot 380 \cdot 0 \mathrm{~g}}=4,26 \mathrm{~A}$

b. Untuk menentukan besarnya nilai arus listrik pada rangkaian daya hubung bintang, maka perlu menggunakan :

- Tegangan hubung bintang $\left(\mathrm{V}_{\mathrm{Y}}\right)$

$$
\left(\mathrm{V}_{\mathrm{Y}}\right)=\frac{V}{\sqrt{2}}=\frac{3 \mathrm{ge0}}{\sqrt{\mathrm{a}}}=219,65 \text { Volt }
$$

- Maka nilai arus waktu hubung singkat adalah:

$$
\mathrm{I}_{\mathrm{Y}}=\frac{p}{\sqrt{\sqrt{8} \cdot V y \cdot \cos \varphi}}=\frac{222 \mathrm{~g}}{\sqrt{3} \cdot 219,65 \cdot 0,8}=7,36 \mathrm{~A}
$$

- Nilai arus hubung segitiga adalah :

$$
\mathrm{I}_{\Delta}=\mathrm{I}_{\mathrm{L}}=4,26 \mathrm{~A}
$$

c. Untuk menentukan besarnya nilai batasan arus listrik MCB 3 phasa pada rangkaian daya hubung bintang segitiga,maka perlu menggunakan :

$\mathrm{I}_{\text {start }}=4 \times \mathrm{I}_{\mathrm{L}}$

Dimana $\mathrm{I}_{\mathrm{L}}=4,26 \mathrm{~A}$

$\mathrm{I}_{\mathrm{MCB}}=\mathrm{I}_{\mathrm{L}} \times 4=4,26 \times 4=17,04 \mathrm{~A}$

d. Untuk menentukan besarnya nilai kapasitas arus listrik Magnetic Contactor 3 phasa pada rangkaian daya,maka perlu menggunakan :
Dimana $I_{L}=4,26$ A

$\mathrm{I}_{\text {kontaktor }}=3 \times \mathrm{I}_{\mathrm{L}}=3 \times 4,26=12,78 \mathrm{~A}$

e. Untuk menentukan besarnya ukuran luas penampang kabel pada rangkaian daya, maka perlu menggunakan :

$\mathrm{A}=\frac{\sqrt{8} \cdot \mathrm{L} \cdot \mathrm{IL} \cdot \cos \varphi}{\mathrm{rWY} \cdot \mathrm{rV}}=\frac{\sqrt{2} \cdot 10,4,26 \cdot 0,8}{0,1,56 \cdot 2,2}=4,8 \mathrm{~mm}^{2}$

\section{B. Hasil Gambar Rangkaian Daya}

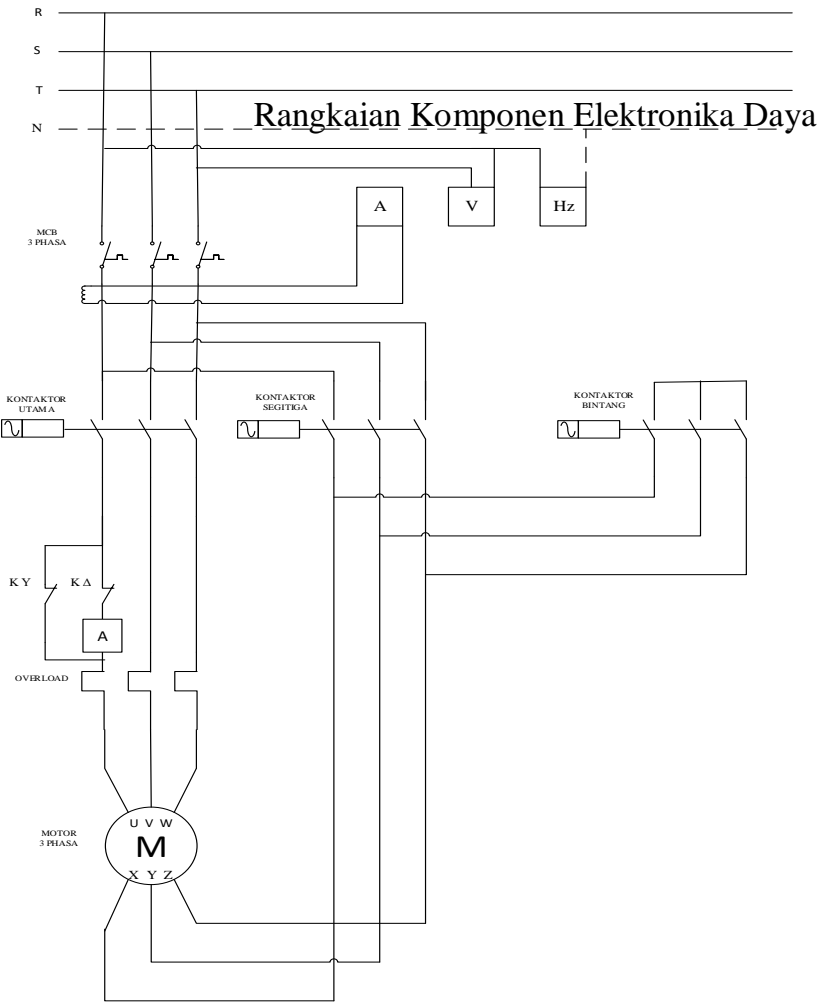

Gambar 3. Rangakaian Daya dengan Pembebanan Beberapa Alat Ukur

\section{Hasil Pengujian Rangkaian Daya}

Hasil Pengujian rangkaian daya dapat ditabulasikan dalam bentuk tabel dibawah ini :

Tabel 1. Pengujian Rangkaian Daya

\begin{tabular}{|c|l|c|c|c|c|}
\hline \multirow{2}{*}{$\begin{array}{c}\text { N } \\
\text { o }\end{array}$} & \multirow{2}{*}{ Input } & \multicolumn{3}{|c|}{ Kontaktor } & \multirow{2}{*}{ Motor } \\
\cline { 2 - 5 } & $\begin{array}{c}\text { K1 } \\
\text { (Utama) }\end{array}$ & $\begin{array}{c}\text { K2 } \\
\text { (Bintang) }\end{array}$ & $\begin{array}{c}\text { K3 } \\
\text { (Segitiga) }\end{array}$ & Bintang \\
\hline 1 & $\begin{array}{l}\text { Tegangan } \\
\text { Masuk 380 } \\
\text { Volt, 50 Hz } \\
\text { dari PLN }\end{array}$ & ON & ON & OFF & Segitiga \\
\hline 2 & $\begin{array}{l}\text { Triping } \\
\text { Timer } \\
\text { Setelah 5 } \\
\text { Detik }\end{array}$ & ON & OFF & ON & Berhenti \\
\hline 3 & $\begin{array}{l}\text { Puss Button } \\
\text { OFF }\end{array}$ & OFF & OFF & OFF & Berhenti \\
\hline 4 & $\begin{array}{l}\text { Tripping } \\
\text { Overload }\end{array}$ & OFF & OFF & OFF & \\
\hline
\end{tabular}




\section{KESIMPULAN}

Untuk merencanakan dan membuat rangkaian daya starting motor 3 fasa, $380 \mathrm{~V}, 50 \mathrm{~Hz}, 3 \mathrm{HP}$ dengan metoda bintang-segitiga adalah dengan cara membuat perencanaan yang meliputi, perhitungan beban yang terpasang, pemilihan MCB sesuai dengan beban, pemilihan luas penampang sesuai dengan beban dan jenis kabel. Dimana dinyatakan dari sumber jala-jala 3 fasa, $380 \mathrm{~V}$ yang dialirkan ke dalam rangkain daya untuk kendali motor 3 fasa, $380 \mathrm{~V}, 3 \mathrm{HP}, 50 \mathrm{~Hz}$ metoda bintang-segitiga, diketahui bahwa beban yang terpasang $3 \mathrm{HP}$, arus pada hubung bintangnya 7,36 A, arus segitiga ataupun arus pada tiap fasanya 4,26A , MCB yang dipakai memiliki kapasitas 17,04A, serta luas penampangnya $4,8 \mathrm{~mm} 2$ dengan jenis kabel NYM.

\section{REFERENSI}

[1] Muhaimin. 2010 Instalasi listrik 1. Pusat Pengembangan Pendidikan Politeknik Bandung : Bandung.

[2] Karamanlis. 2010. Rangkaian Daya dan Kendali Motor Induksi 3 Fasa. Universitas Negeri Jakarta: Jakarta Baktir Achmad, 1992, " Perkiraan Luas Daerah Penyebaran Polutan Partikular : Studi khasus Cerobang PT Semen Gresik ", Laporan penelitian, PUSLIT ITS

[3] Ayu, Ervina. 2011. Pengontrolan Motor Induksi 3 Phasa. Jurnal Penelitian Enginering. Universitas Brawijaya : Malang.

[4] Hidayat, Riduwan 2012. Aplikasi Motor Induksi Tiga Phasa. Makalah Seminar Kerja Praktek. Universitas Diponegoro : Semarang.

[5] Andriani. 2014. Kontrol Kecepatan Motor Induksi. Jurnal Jurusan Teknik Elektronika. Politeknik Elektronika Negeri Surabaya Kampus PENS-ITS Sukolilo : Surabaya.

[6] Amfa (2012) kuliahelektroustj@gmail.com Bahan Ajar Materi Kuliah elektro (catatan matakuliah) online USTJ-PAPUA. Diunggah tanggal 10 November 2012.

[7] Budiono, Bambang Sri (2013) Jenis Panel Listrik dan Panel Tegangan. Diunggah tanggal 1 februari 2013 segitiga-info.blogspot.com

[8] Surya,Danang (2012) Gambaran Penerencanaan Panel Rangkaian Daya BintangSegitiga http://danangsurya16.blogspot.com/

[9] Nur Alif, Totok (2012) Dasar Kontrol Konvensional Kontaktor. Teknik Kelistrikan. SMK Negeri 2 Kota Probolinggo : Probolinggo Jawa Timur https://www.totoktpfl.wordpress.com/

[10] Adji. (2010) Prinsip Dasar Instalasi Listrik SMK Negeri 1 Bangil http://listriksmknesaba.blogspot.com/2010/04/prinsip-dasarinstalasi. Jurusan Listrik. SMK Negeri 1 Bangil. 